\title{
Revisiting Educational Research Through Morin's Paradigm of Complexity
}

\section{A Response to Ton Jörg's Programmatic View}

\section{MICHEL ALHADEFF-JONES}

Teachers College, Columbia University (USA)

EXPERICE Research Center, University of Paris 8(France)

\section{Foreword}

I am very grateful to the editors of Complicity for inviting me to react to Ton Jörg's paper and to Ton Jörg himself for sharing his ongoing thought about education and complexity. As a Swiss French-speaking scholar, living in the US, I can only enjoy submitting to an English-speaking Canadian journal a reflection on a paper written by a Dutch colleague. I regularly observe the difficulties inherent in confronting different cultures of research in education and the lack of opportunity to promote and reflect on the specificities of such a dialogue.

The idea of complexity evolved following a history rich in theories and concepts. This notion can be defined and understood according to heterogeneous interpretations referring to epistemologies and methodologies of research sometimes in opposition with each other. In Latin countries, the use of this notion has a specific history, both dependant and dissociated from theories usually associated under the umbrella of Complexity Theory (Alhadeff-Jones, 2008a). Because such differences are embedded not only in distinct theoretical traditions, but also and above all in the history of heterogeneous cultures of thought, and in the history of academic institutions as well, it seems crucial to me not only to reflect on, but also to confront what are the differences between plural interpretations of complexity. This belief is at the core of my reading of Jörg's paper. 
Because it grounds most of my academic work, the reflection developed in this paper follows the epistemological and anthropological critique characterizing the "paradigm of complexity" proposed by Edgar Morin (1977/1992, 1980, 1986, 1991, 2001, $2004,2007,2008)$. It invites us to question the way one conceives changes and transformations brought by the use of the notion of complexity itself. In this perspective, instead of discussing Jörg's paper focusing on the content of his theoretical propositions, my intent is to question and comment on what I interpreted as being some of the implicit assumptions which frame his reflection. The aim of this paper is therefore to question the way one conceives the use of a specific theoretical approach (i.e., theories associated with the concept of complexity) in order to promote changes in educational practices and theories. The position I am adopting here translates indeed the conviction that any reform of thought has to be conceived in conjunction with a reflection about the idea of reform itself (Morin, 1999). It is therefore assumed that the use of the notion of complexity, to be critical and to bring significant changes, supposes not only to use a specific theoretical vocabulary, but also and above all to change the way scientific activity itself is conceived in order to bring about such a transformation.

\section{Morin and the Paradigm of Complexity}

In France, Edgar Morin appeared as a pioneer when he started to introduce at the end of the 1960's a reflection on the stakes inherent in a complex way of thinking. The critical aim of his project fundamentally challenges the ways one conceives knowledge production, from an epistemological, psycho-socio-anthropological and ethical point of view as well. It involves in particular a recursive loop linking the processes of production of scientific knowledge to the processes of evaluation of this production.

Morin (1990/2008, 2007) locates his reflection at the paradigmatic level. He challenges the principles guiding what he identifies as "paradigm of simplification": a conception of science privileging unidimensionality, abstraction, and decontextualization. Doing so, he locates himself in a broader intellectual movement which denounces a conception of science conditioned by the following: the hegemony of disjunction, reduction and calculi; the reinforcement of a logic of hyper specialization; and the perpetuation of the separation between the object of research, researchers' moral consciousness and the awareness of psycho-socio-anthropological variables which determine their activity.

The emergence of the paradigm of complexity has to be understood considering the limits of the paradigm of simplification. However, Morin's conception does not suggest abandoning such a perspective. He recognizes the value of an instrumental and utilitarian intelligence aiming to respond to practical needs, overcoming uncertainty and ambiguity, and formulating clear and accurate diagnoses. He prefers to privilege a dialogical combination: using traditional scientific approaches and, at the same time, being able to transgress their assumptions when they are no more operational (Morin \& Le Moigne 1999). Therefore, a complex way of thinking (pensée complexe) suggests challenges instead of solutions. The critical stake associated with a complex way of 
thinking requires therefore being able to tolerate the continuous negotiation between order and disorder. It also involves rethinking constantly the organization legitimizing one's own statements. Considering the lack of a granted method to cope with the challenges he is raising, the position assumed by Morin is grounded in a radical uncertainty. It depends on a permanent process of self-reflection bringing researchers to continuously question their doubts, their ignorance and their confusion.

Morin stresses the fact that sciences have to be considered as object of sciences, including the scientists as subjects of this object. This perspective is grounded in a logic privileging the recognition of circularities animating the production and the organization of knowledge. According to this view, the six volumes of Method (Morin 1977-2004) can be conceived as a manifesto for a "science of science". On one side, his contribution claims the implication of the researcher. On the other side, it advocates for an evaluation of the knowledge produced, based on this knowledge itself, instead of referring it to an evaluative process supposed to be neutral and external (traditional epistemology). From the point of view of the researcher, a complex way of thinking sends back to the idea of cheminement. It suggests conceiving the scientific process as a continuous learning, source of change, grounded in the experience of doing research itself. Morin conceives therefore the writing of science following an essayiste and strategic logic: "[...] open and not hiding its own wandering, without renouncing the fleeting truth of its own experience." (Morin, Motta \& Ciurana, 2003: 19; my translation)

From an educational perspective, a complex way of thinking may be understood as a method of learning involving human error and uncertainty (Ibid.). It involves taking in consideration both the individual and collective experiences grounding any activity of research, and - more deeply - the processes of learning (formation) associated with them (Alhadeff-Jones, 2005, 2007, 2008b, 2008c).

According to Morin's contribution, the following reflections suggest one to revisit and question Jörg's argument through at least four types of tensions shaping the way one does research: program versus strategy, prescription versus interpretation, monoreferentiality versus multireferentiality, distance and generalization versus implication and contingency.

\section{Program versus Strategy}

In his paper, Jörg describes clearly - starting with his title - his intent to define the basis of "a programmatic view" aiming to rethink the way learning and development are conceived in educational sciences. I do not challenge his motivation, however it seems important for me to question first the use of the notion of "program" and what it may involve. As stressed by Morin (1980, p. 224-225, my translation), literally, the expression refers to "what is written in advance". A program designates:

[...] a set of codified instructions which, when the specific conditions of their execution appear, allow an apparatus [appareil] to trigger and control defined and coordinated sequences of operations to get to a specific result. (Ibid.) 
The notion of program refers therefore to a predetermined organization of action. Because it only reproduces predefined codes (e.g., embedded physically, biologically or culturally, and expressed through artificial or natural languages), a program requires a steady environment to be executed. It can only manage superficial unknown factors or resistances and it has a low tolerance for errors (Ibid.).

There is no doubt that the "programmatic view" proposed by Jörg suggests far more flexibility when its implementation is considered. The value of his reflection is in many ways exploratory and it deserves to be recognized as such. It appears therefore relevant to complexify its programmatic dimension by stressing the strategic component associated to it. As it is the case for a program, a strategy involves coordinated sequences of operations. What makes it be distinct appears in the fact that a strategy is grounded in:

[...] not only initial decisions triggering [actions], but also [in] successive decisions, taken based on the revolution of the situation; what can bring modifications in the succession or even in the nature of the planned operations. [...] the strategy constructs, deconstructs, reconstructs itself, based on events, unknown factors [aléas], countereffects, reactions perturbing the ongoing action. [It] requires the aptitude to engage an action in uncertainty and to integrate uncertainty in the management of action. Strategy requires skills and initiative. (Ibid.)

In order to embrace the complexity of a reform, such as the one proposed by Jörg, any "programmatic view" requires a strategic way of thinking questioning the uncertainties which determine its own evolution. The question emerges therefore: how to cope with such uncertainties?

\section{Prescription versus Interpretation}

Considering both its intent and its style, Jörg's narrative and the "programmatic view" it unfolds articulate a set of recommendations prescribing what should be done in order to develop a specific vision of education and "open the vistas of re-inventing the field of learning and teaching" (Jörg, this issue, p. 2, emphasis original). I have no doubt about the fact that discursive practices shape the way one interprets "reality". I also do not doubt that changing the ways one represents an issue may affect the way one interacts with it. However, the relationship between the re-interpretation of a situation and its transformation - and I am sure Jörg himself won't contradict me - is far from being simple and linear. It appears therefore critical to question and elaborate the resistance encountered when someone proposes to reinterpret a "reality" and the non-expected consequences it can bring; what Morin (2007) calls the "ecology of action".

Scientists and educators are not different from anyone else; they are sometimes able to manifest a strong ability to resist to change. Resistance per se is not necessarily bad. It usually expresses underlying dynamics linked to the libidinal, emotional, cognitive, but also social, cultural, political or ethical dimensions (to name a few) determining any situation. Strategically considering educational research involves therefore understanding and respecting the uncertainties associated with resistance and change. 
As shown by clinical and organizational psychology, such a process cannot be prescribed as, most of the time, prescriptions contribute to increase resistance (Argyris, 1993; Watzlatwick, Weakland \& Fisch, 1974). It appears therefore needed to understand where resistance is coming from and what is it contributing to express. In my view, such a strategy requires the adoption of a comprehensive approach (Schurmans, 2006) instead of a prescriptive one - valorizing a hermeneutical and critical conception of science in general (Habermas, 1971) and in educational research and practice in particular.

Privileging a comprehensive approach would suggest, before instrumentalizing a path of action, researchers to interpret the reasons explaining why a linear and simplifying conception of learning is - if it is the case - dominant. It would also bring the question of when and why it is not always the case. Jörg refers to the dilemmas which brought educational research to follow natural sciences models. No doubt that it is part of the answer. Interpretations are however diverse and their multiplication is needed in order to fine-tune the understanding of the denial of complexity observed among educational research, and the assumptions which justify it.

From a recursive perspective, it seems also needed to question what involves the adoption of a position claiming the value of complexity, from a theoretical perspective, but also from an experiential point of view, considering its psychological, social, cultural, or ethical implications for educators and researchers. Where do the strong convictions animating a researcher (Jörg, you or myself) come from? What resources sustain it? Beyond one's own readings, what are the learning experiences developed by a researcher through her/his own past life which feed today one's own present epistemic beliefs? The use of the theoretical contributions evocated in Jörg's paper emerges from a history, at the junction between researchers' life histories, the history of human knowledge and - in this case - the history of educational sciences and educational practices. It also translates power dynamics among disciplines, scientists and practitioners which have to be acknowledged if one wants to influence them.

\section{Monoreferentiality versus Multireferentiality}

Using complexity theories in education is problematic, because to a large extent those theories have emerged from (as well as contributing to the emergence of) fields of research missing epistemological considerations regarding the specificity of human complexity (by contrast to physical, computational or biological complexities) (AlhadeffJones, 2008a). Because its current use is connoted by physical theories, the notion of "interaction" cannot be taken for granted in education. Phenomena studied in education involve heterogeneous forms of organization (physical, biological, psychological, social, etc.) grounded in logics incommensurable with each other, and far more complex than physical phenomena themselves (Ardoino, 1993). Such multireferentiality gets expressed, linguistically, through the use of various notions and concepts which appear in affinity with "interaction" but also carry their own meanings: relationship, dialogue, affiliation, rapport, transference, influence, etc. The risk of focusing on a single one (such 
as "interaction") is that it quickly brings to reduce the spectrum of phenomena and theories recognized as relevant for the purpose of the inquiry. It is probably this reason which brought Morin to privilege "macro-conceptualization" as a strategy of research aiming to establish and question links and relationships between notions and concepts, and by extension between and beyond disciplines. It is indeed needed to question how the notion of "interaction" can be complexified in order to avoid reducing the phenomena it is supposed to describe through a set of assumptions framed by a single referential (may it be physicalist or cognitivist).

The notion of interaction appears generally at the core of definitions of complexity (often characterized by a large number of interactions with a high level of qualitative variety) (Alhadeff-Jones, 2008a). In Method (Morin, 1977-2004), it appears as the turntable notion located at the core of a macro-concept grouping the concepts of order, disorder and organization. Interaction appears necessary to a complex definition of those concepts. It also requires them to be defined. On a physical level "[...] the rules of interaction [...] constitute the keystone of cosmic order, its "natural laws"." (Morin, 1977/1992, p. 47). At the same time, interactions are unconceivable without disorder (inequalities, turbulences, etc.) constituting their conditions of emergence. According to Morin, a definition of the concept of interaction can be formulated as such:

Interactions are reciprocal actions modifying the behavior or the nature of elements, bodies, objects, phenomena present actually or influentially. Interactions (1) suppose elements, beings or material objects capable of encountering each other; (2) suppose conditions of encounter, that is to say agitation, turbulence, contrary fluxes, etc.; (3) obey determinations / constraints inherent to the nature of elements, objects or beings in encounter; (4) become in certain conditions interrelations (associations, linkages, combinations, communication, etc.) that is to say give birth to phenomena of organization. [...] (Ibid.)

If interactions have a critical role in the development of organized systems, the complexity they introduce comes also from the fact that they may be of different nature. A complex living phenomenon can thus involve complementary interactions (associations, societies, symbiosis, mutualisms), but also competitive (competitions, rivalry, etc.) and antagonistic ones (parasitism, predation, etc.) (Morin, 1980, p. 21) Depending on the level of organization considered, one could finally distinguish interactions based on their physical, biological, or psycho-socio-anthropological expressions.

Locating at the core of a learning theory the concept of interaction supposes therefore to make explicit what kinds of action and relation one is referring to. It also requires distinguishing it from other expressions, such as those above mentioned. More broadly, its use requires the definition and justification of what are the interacting "elements" considered. According for instance to Pineau's (2000) learning theory, inspired by Rousseau and Morin, learning (formation) involves intertwined interactions maintained with oneself (auto-formation or self-directed learning), with other (hétéroformation or hetero-learning) and with the physical and natural surrounding environment (écoformation or ecolearning). 
How does one conceive therefore learning interactions? As physical (proxemic), biological, discursive, cognitive, emotional, social, and/or cultural ones? Each of these perspectives suggests referring to theoretical and pedagogical referentials already existing. It does not necessarily suggest the "reinvention" of an educational language, but rather the reflection on the way heterogeneous vocabularies and logics can be - or not - articulated with each other.

One of the main stakes appears, in my view, to consider the multireferentiality of educational situations (Ardoino, 1993) and the heterogeneity of languages used to interpret them. The uncertainty of the researcher aiming to understand strategically the way heterogeneous languages are articulated involves therefore the making of choices, to make them be explicit and to justify them in regard of the contingencies of her/his own environment.

\section{Distance and Generalization versus Contingency and Implication}

The "programmatic view" proposed by Jörg takes the reader off to elevate her/him to a pretty high altitude. As I was reading his paper, I often asked myself: what kind of practices is he referring to? What kind of subjects, individuals or collectivities has he in mind? In spite of referring to a particular moment in the history of sciences and education, the reflection proposed by Jörg often appeared decontextualized.

Post-modern, post-structuralist, and critical contributions developed in education during the past decades have already shown the limits of statements claiming the universal value of a theory or a practice (Alhadeff, 2002). They invite researchers to be cautious when the relationship between generality and singularity is considered. Such a dialogical relationship should be, in my view, at the core of a complex way of thinking.

Privileging a complex strategy of research requires indeed the exploration of educational theories, considering them at the light of the environment in which they are emerging. It also suggests the exploration of what makes the singularity of both a learning situation and a research environment, considering the micro and macrohistorical background which inform them. A science of complexity is also, and maybe above all, a science of contingency and singularity.

Does it mean that a complex approach of learning can only be relative? According to Morin, the promotion of the paradigm of complexity suggests researchers to reflect on the contradictions, complementarities and antagonisms inherent to the relationships between generality and singularity. Any "system" requires a subject who isolates it, cuts it up, qualifies it, hierarchizes it, based on her/his selective interests and the cultural and social context of scientific knowledge (Morin, 1977/1992). In educational sciences, "systems" always involve human factors. Their study is not equivalent to the study of physical entities. In addition to a history, they always involve meanings, values, and behaviors, which are never indifferent to the researchers who study them, may it be consciously or not (Devereux, 1967).

One way to reflect on the dialogic between generality and singularity is to take into consideration the implication of the researcher her/himself. In Morin's work, it gets 
translated through the significant autobiographical contribution he made and the way he anchors the elaboration of his epistemological position in his own life history (in English, see Kofman, 1996). At a more modest level, it can bring every researcher to position her/his own writing based on the expression of the contingency and the filiations framing one's own beliefs, assumptions and practices.

Thinking about interactions supposes one to conceive those which involve the researcher her/himself and which allow one to consider her/his commitment, choices and positions regarding epistemological, ethical and existential issues, as they appear influenced by emotional, cognitive, social, historical or political determinants.

Several traditions of intervention and research in education have followed such a path. In France, one can mention among others the role played since the early 1970's by Analyse Institutionnelle (Lamihi \& Monceau, 2002), the influence starting in the early 1980's of Life History and biographical approaches in adult education (Dominicé, 2000) or the contribution of Psychosociologie Clinique (Barus-Michel, Enriquez \& Levy, 2002). Such traditions suggest researchers to explicitly approach the complexity of learning through a hermeneutical approach privileging their subjectivity and the process through which interpretations are produced. From this perspective, what makes the meaning of both the learning activity and the research process emerges from the co-interpretation inherent in the discursive interactions between researchers and between agents implicated in the educational context considered.

\section{Opening}

The use of the notion of complexity can never be taken for granted. According to a complex and recursive perspective, it appears that a reflection on the interactional and non-linear dimension of learning requires a researcher to conceive simultaneously the interactions and non-linearities which bind her/him to the phenomena that s/he study, to the theories that $\mathrm{s} /$ he borrows or creates, to her/his surrounding environment and to he/his own existence, as they all determine her/his own ways of knowing.

Recognizing and privileging the interpretive dimension of research brings one to complexify the relationships between the production of scientific discourses and the "realities" to which they are referring. "Re-inventing" a pedagogical discourse necessarily involves the emergence of conflicts of interpretation and antagonisms producing as well as expressing the resistances determining the strategies implemented by researchers (Alhadeff-Jones, 2007, 2008b, 2008c). This comment itself expresses resistances, born from the confrontation between heterogeneous referentials (theoretical as well as cultural ones). Looking for a complex understanding of education requires one to question such heterogeneity (between researchers, learners, theories, etc.)

In this paper, I have claimed that such a process cannot be programmed, prescribed or generalized following a detached approach without operating some problematic reductions. It should instead aim to articulate program and strategy, prescription and interpretation, heterogeneous interactions and languages, generalization and singularity, distance and implication. From this point of view, the adoption of a complex way of 
thinking supposes in my view to recognize the uncertainties, unknown factors, aléas, and risks associated to any process of theoretical exploration. It suggests that researchers produce interpretations inscribed in a hermeneutical process which recursively requires the privileging of a hermeneutic of research. It suggests that researchers recognize and question the heterogeneous nature of the referentials used or implemented. It finally requires that they recognize and privilege their own implications: the ways researchers' own experience echo with the life of those they are interacting with."'

\section{References}

Alhadeff, M. 2002. Les Enjeux de la Critique dans le Paysage Anglo-Saxon de l'Education: Petite Course à travers Champs. Pratiques de Formation / Analyses 43: 131-144.

-. 2005. "Complexité de la Critique et Critique de la Complexité en Formation. "In Complexité de la Formation et Formation à la Complexité, edited by J. Clénet and D. Poisson, 227-242. Paris: L'Harmattan.

Alhadeff-Jones, M. 2007. Education, Critique et Complexité: Modèle et Expérience de Conception d'une Approche Multiréférentielle de la Critique en Sciences de L'Education. Doctoral Dissertation, University of Paris VIII.

-. 2008. Three Generations of Complexity Theories: Nuances and Ambiguities. Educational Philosophy and Theory 40 (1): 66-82.

-. 2008. Concevoir le Développement d'un Rapport Critique à la Complexité dans l'Activité de Recherche. Chemins de formation 12/13: 104-12.

-. 2008. "Promoting Scientific Dialogue as a Lifelong Learning Process." In A Vision of Transdisciplinarity. Laying Foundations for a World Knowledge Dialogue, edited by F. Darbellay, M. Cockell, J. Billotte and F. Waldvogel, 104-112. Lausanne, Switzerland: Swiss Federal Institute of Technology Press.

Ardoino, J. 1993. L'approche Multiréférentielle (Plurielle) des Situations Éducatives et Formatives. Pratiques de Formation / Analyses 25-26: 15-34.

Argyris, C. 1993. Knowledge for Action. A Guide to Overcoming Barriers to Organizational Change. San Francisco: Jossey-Bass.

Barus-Michel, J., Enriquez, E., Lévy, A., ed. 2002. Vocabulaire de Psychosociologie. Ramonville, France: Eres.

Devereux, G. 1967. From Anxiety to Method in the Behavioral Sciences. The Hague: Mouton.

Dominicé, P. 2000. Learning from Our Lives. Using Educational Biographies with Adults. San Francisco: Jossey-Bass.

Habermas, J. 1971. Knowledge and Human Interests. Boston, MA: Beacon Press.

Kofman, M. Edgar Morin. 1996. From Big Brother to Fraternity. London: Pluto Press.

Lamihi, A. and G. Monceau, ed. 2002. Institution et Implication. Paris: Syllepse.

Morin, E. 1977/1992. Method. Towards a Study of Humankind (Volume 1: The Nature of Nature). New York: Peter Lang.

-. 1980. La Méthode (Vol.2) La Vie de la Vie. Paris: Seuil.

-. 1986. La Méthode (Vol.3) La Connaissance de la Connaissance. Paris: Seuil.

-. 1990/2008. On Complexity. Cresskill, NJ: Hampton Press.

-. 1991. La Méthode (Vol.4) Les Idées. Leur Habitat, leur Vie, leurs Moeurs, leur Organisation. Paris: Seuil.

-. 1999. La Tête Bien Faite. Repenser la Réforme, Réformer la Pensée. Paris: Seuil.

Morin, E. and J.-L. Le Moigne. 1999. L'intelligence de la Complexité. Paris: L'Harmattan.

Morin, E. 2001. La Méthode (Vol.5) L'Humanité de l'Humanité, l'Identité Humaine. Paris: Seuil.

Morin, E., Motta, R. and E.R. Ciurana. 2003. Eduquer pour l'Ere Planétaire. La Pensée Complexe comme Méthode d'Apprentissage dans l'Erreur et l'Incertitude Humaines. Paris: Balland. 
Morin, E. 2004. La Méthode (Vol.6) Ethique. Paris: Seuil.

-. 2007. "Restricted Complexity, General Complexity. "In Worldviews, Science and Us, edited by C. Gershenson, D. Aerts and B. Edmonds, 5-29. London: World Scientific.

Pineau, G. 2000. Temporalités en Formation. Paris: Anthropos.

Schurmans, M.-N. 2006. Expliquer, Interpréter, Comprendre. Le Paysage Épistémologique des Sciences Sociales, Carnets des Sciences de l'Education. Geneva, Switzerland: University of Geneva.

Watzlawick, P., Weakland, J. and R. Fish. 1974. Change. Principles of Problem Formation and Problem Resolution. New York: W.W. Worton.

\section{About the Author}

Michel Alhadeff-Jones is an Adjunct Assistant Professor of Adult Education at Teachers College, Columbia University and works as an independent researcher. He is a psychologist specialized in selfdevelopment and adult training, as well as a philosopher of education. Before starting his collaboration with Teachers College in 2003, he worked for many years as a Teaching and Research Assistant at the University of Geneva (Switzerland). In Europe, he is currently associated to the French Laboratory of Research Experience, Cultural Resources and Education (EXPERICE, Universities of Paris 8 / Paris 13). His teaching and research interests are in critical and complexity theories applied to adult and higher education, biographical approaches, time studies, transdisciplinarity and science studies. He has published several papers and chapters of books related to these themes. Additional information and papers are available at www.implexus.org. He can be contacted at the following email address: education.critiques@gmail.com.

(C) Copyright 2009. The author, MICHEL ALHADEFF-JONES assigns to the University of Alberta and other educational and nonprofit institutions a non-exclusive license to use this document for personal use and in courses of instruction provided that the article is used in full and this copyright statement is reproduced. The author also grants a non-exclusive license to the University of Alberta to publish this document in full on the World Wide Web, and for the document to be published on mirrors on the World Wide Web. Any other usage is prohibited without the express permission of the authors. 